\title{
El orden de los acontecimientos en Shakespeare
}

\author{
Cándido Pérez Gállego
}

«Un padre es asesinado. Su hijo toma conciencia. Descubre la verdad y hace justicia. Es asesinado.» El esquema de Hamlet se vuelve sobre si mismo, con su irónica simetría para generar nuevos argumentos. El orden de los acontecimientos en el teatro de Shakespeare desvela una visión patética de la historia, una imagen conflictiva de la vida del hombre. Apenas nos encontramos en una obra suya sabemos qué es lo que el héroe busca. Sus metas están dentro o fuera del escenario, pero, muchas veces, él mismo nos lo dice. En sus labios se expresa la frase objeto de su vida: conquistar una mujer, vengarse del traidor, conspirar contra el Monarca, volver a tierra firme. Conocemos las dificultades que esa ardua empresa trae consigo, la «mitología» que será preciso desplegar para que las naves del proyecto avancen... El héroe va «componiendo lenguajes», «respondiendo dificultades», «reaccionando ante imprevistos».. Su actuación tiene todos los componentes de una «teoría del comportamiento» en la que observásemos «el modo de conseguir Julieta», «el modo de matar a Ricardo II», «el modo de perdonar a Alonso» y este método nos interroga, salta del escenario al espectador y le expresa cómo las metas se alcanzan.

Shakespeare atraviesa su propia obra, sus íntimas analogías y, como Northrop Frye analiza en Fools of Time ${ }^{1}$, añade a cada situación lo procedente de otras. Organiza un «continuo dramático» donde la Morality de los actos se abren en diálogo sincero. Departen «Virtud» e «Inocencia», hablan «Poder»y «Conspiración», discuten «Padre» $\mathrm{e}$ «Hijo». Esta forma de hacer del acontecimiento un módulo generador de situaciones nos senala un arte donde la modificación viene del medio circundante. Ese mensajero que se abre paso, ese pañuelo que alguien recoge, esa forma

1. Fools of Time by Northrop Frye. London: Oxford University Press, 1967, $121 \mathrm{pp}$. 
de familiarizares con los venenos tiene como resultado un «gran error», un destino fatal que lleve del orden al caos, que haga que la felicidad se quebrante. Y, por tanto, entender Shakespeare», alguien lo ha hecho con rigor $^{2}$, es comprender cómo se rompe un equilibrio para, por una irónica función de «homeóstasis», volver de nuevo al mismo. Analizar una dinámica social donde el reposo es amenazado por imprevistos cambios. Imaginar una «teoría del ocio», pensamos ahora en sus comedias, donde un trasvestismo moral acecha. Producir en el ámbito de la realidad que se nos entrega: «Un rey debe gobernar», la propuesta «Un rey debe ser asesinado». Tal imagen hace que ni un solo rincón de su obra no esté sujeto a crítica. Ni que cuando se llegue al plano más lejano al escenario reaparezca una forma de hablar que nos indica que somos observados, que un «suceso fatal» nos ronda. Esta es la dinámica que mueve Macbeth, Richard III o King Lear. Que las cosas cambien, que lleguen a un punto de guerra y caos que vuelvan a un punto de reposo. El ciclo ha pasado por las más dilatadas situaciones. Se ha hecho del escenario una metáfora del tema de la caída y del ímpetu del hombre por renacer.

El orden de los sucesos parte de una situación inicial «neutra» y pronto aparece el conflicto ante nuestra vista. Se trata de un suceso inesperado que rompe la armonía del comienzo, que deja entrever su dimensión de «conspiración»o «error fatal»y conduce de modo irrevocable a una catástrofe. Siguiendo ideas de W. H. Clemen ${ }^{3}$, se debe pensar que hay una disposición de elementos lingüísticos que llevan de la armonía al caos o viceversa. Hasta sospechar que hay una simetría global de actuaciones que quedan plasmadas en este esquema:

\section{HistORIAS Y TRAGEDIAS}

1) «Si hay poder hay conspiración» (Richard III o King Lear).

2) «Si hay amor hay muerte» (Romeo and Juliet o Antony and Cleopatra).

3) «Si hay deseo de justicia hay fracaso» (Hamlet o Henry IV).

\section{Comedias Y ROMANCES}

1) «Si hay poder hay milagros» (Midsummer Night's Dream o The Tempest).

2. Understanding Shakespeare by E. F. C. Lupowrk. Cambridge: At the University Press, 1964, $266 \mathrm{pp}$.

3. "In The Tempest, the actual catastrophe is at the beginning, and not at the end or in the middle of the play. And everything derives and develops from this beginning.) The Development of Shakespeare's Imagery by W. H. CLEM EN. Methuen: London, 1967 (1951), p. 182. 
2) «Si hay amor hay final feliz» (As You Like it o Pericles).

3) «Si hay deseo de justicia hay perdón» (Measure for Measure o Cymbeline).

Estas relaciones nos dejan al descubierto que la trama de los hechos no tiene una libertad absoluta, sino que partiendo de lo estable busca el espacio de lo armónico $\mathrm{y}$, como hemos analizado en otra ocasión ${ }^{4}$, se trata de un ámbito que engloba lo mismo «recognition» como «rebirth», y que hace que la «búsqueda de la identidad perdida» (Twelfth Night es buen ejemplo) un ejercicio de metafísica. Con ese lema de que cada espacio tiene un valor y cada situación un sentido avanza la acción en Richard III o en Much Ado About Nothing, destruyendo la ambigüedad haciendo de cada acto una pregunta por responder.

Y por eso la línea básica del conflicto (conquista del poder, conquista de la mujer, conquista del orden) se abre en un festival de «frases complementarias» donde la sociedad actúa de modo pasivo. Y hasta en obras clásicas, donde el sometimiento al pasado es más obvio, Shakespeare no sabe deslindar su propia dimensión de «fabulador» $\mathrm{y}$ «testigo», como G. Wilson Knight pone de manifiesto ${ }^{5}$. Son unas construcciones de la realidad que se reiteran, son un vistoso equilibrio de «combinatoria moral» que como superando un esquema de Propp nos hiciera estas proposiciones :

Analizar todo lo que
le puede pasar $\left\{\begin{array}{ll}a) & \text { a un Rey } \\ b) & \text { a una hija abandonada } \\ c) & \text { a unos enamorados }\end{array}\right\}$ en el contexto $H$

En tales circunstancias el hecho de que «lo perdido se encuentre» pone puntos claros a un proceso que partiendo de la armonía de la tautología (A y B son felices, A es un rey, A es un príncipe...) va acercándose a un punto de conflicto. Los héroes trágicos de Shakespeare, que Lily B. Camphell estudia con talento ${ }^{6}$, se esfuerzan por mantener su status,

4. Shakespeare y la política por Cándido Pérez Gállego. Madrid: Narcea, 1971, 246 pp.

Dramática de Shakespeare por Cándido Pérez Gállego. Zaragoza: Las Ediciones del Pórtico, 1974, 308 pp.

5. "In Antony and Cleopatra, though the love of the protagonist is shown to us as untrusting and untrustworthy, a spiritual and passionate thing tossed tempestuously on the waters of temporal existence, yet, by the synchronizing of faith and death, we are left with a vision of timeless instantaneous ascension in death to love, which is life.) "Myth and Miracle» en The Crown of Life by G. Wilson Knight. London: Methuen, 1965 (1947), p. 17.

6. Shakespeare's Tragic Heroes by Lily B. CampbeLx. London: Methuen, 1972 (1961), $296 \mathrm{pp}$. 
quieren seguir su propia situación. Troilus desea seguir siendo feliz, Hamlet quiere en realidad ser Rey, Julieta continuar con quien ama.

Lo que más nos sobrecoge de Shakespeare es su capacidad de salir victorioso de las situaciones más difíciles. Cuando ya una escena está saturada da un brusco giro a la acción y nos lleva hacia lugares remotos, donde un nuevo «teatro» comienza. El mismo modo de hablar de sus personajes es una prueba de su dinámica escénica: es como flechas que llevan a un punto situado fuera del escenario, parece golpear con insistencia un texto que rodease The Globe, no deja libertad de actuación sino que somete a palabras un ceremonial de provocaciones. Así se responde a Ricardo II, Enrique IV o Enrique VI. Desde una conciencia de que el Parlamento escucha, que hay una ordenación de circunstancias que dan a su palabra un lugar preciso. Es entonces cuando el Monarca se ampara en su status (en su «máscara») y hace de Rey, realiza la más sublime actuación de «héroe mesianista» que sea posible. Añade a su boato, la metáfora, las imágenes de la Naturaleza, el ceremonial. Se constituye en centro del universo hablado. Su disfraz responde.

El orden de los acontecimientos es claro: desde la anarquía hacia la paz, desde el caos hacia el renacer. The Tempest empieza con un naufragio y una tormenta, termina con una escena de perdón y reconciliación. El sosiego de Enrique IV hablando con su hijo delata la tempestad interior de saberse asesino de Ricardo II, y el ciclo con el tema del «hijo regenerado» se patentiza en el Príncipe Hal. También se vuelve de la muerte en Cymbeline, The Winter's Tale o Pericles. La familia queda completa, los seres perdidos vuelven a la vida, una felicidad basada en la conquista de lo extraviado hace su aparición. El «regreso» de Hermione del «reino de los muertos» tiene su contrapunto en el hallazgo de la felicidad de Ferdinand, el príncipe «huérfano» que en Miranda eree ver una diosa. $\mathrm{Y}^{T}$ por ello las obras finales son como una conquista del tema bucólico, una vuelta a los momentos de Charlecote. «Old Stratford», la finca que Shakespeare compra a los Combe en 1602, es en efecto un Paraíso, lo mismo que en The Merchant of Venice será el mundo encantado de Belmont. Porcia era allí la diosa y la conquista sexual le esperaba: este tema de ritual hacia lo femenino, que une As You Like It con Twelfth Night, deja al descubierto la búsqueda de la compañía, el proceso de que conversión de todo en todo, la apotesis de que la belleza femenina ees universal y eterna. Rosalinda y Viola son la prueba y su «vuelta al sexo original» exponente de una mimesis creadora.

El disfraz se ha hecho necesario. La apariencia ha suplantado a la realidad. El milagro de «volver a ser lo que éramos» tiene la belleza de un ritual de la Arcadia, y por eso Falstaff, al «no poder ser más lo que es», 
se hundirá en amargura y desolación. Ha habido un orden, se ha desarrollado un proceso que desde la situación de privilegio ha llegado al conflicto para volver a una meta de identificación. Troilus and Cressida deja la verdad al descubierto, igual que Romea and Juliet pone de relieve un destino negativo, o Macbeth en la figura del Rey Duncan recuerda ese «viejo legislador» que como el Rey Hamlet o del Rey Lear han de ser asesinados paar que la historia dé cuentas de su rumbo. Las batallas se repiten, y entre los alaridos del combate surge el vacio humano, el camino sin rumbo. La deserción de la gracia que a alguien en Antony and Cleopatra persigue.

Los oficios se reiteran. Recordemos algunos: jardineros o mozos de cuadra (Richard II), marineros (The Tempest), sepultureros o cómicos (Hamlet), pastores (The Winter's Tale), soldados (Henry IV). Hablan desde su propia condición y añaden a sus palabras el sello de una responsabilidad moral ante el drama de la historia que viven. De aquí el inolvidable momento en el que unos jardineros dan a una Reina que les escucha la más implacable lección de teoría política. Estamos en Richard II:

«Go. bind thou up you dangling apricocks,

Which like unruly children make their sire

Stoop with oppression of their profigal weight,

Give some supportance to the bending twigs.

Go thou, and like an executioner

Cutt off the heads of too fast growings sprays,

That look too lofty in our commonwealth

All must be eren in our government...»

(«Id a atar esos jóvenes albaricoques balanceantes, que como hijos desobedientes, hacen al padre agacharse con la opresión de su peso pródigo: apuntalad las ramas que se doblan. Ve tú, y, como un verdugo, corta las cabezas de las ramas que crecen demasiado deprisa y se elevan con demasiada altivez en nuestra república : todo debe ser por igual en nuestro gobierno»)

(Traducción, J. M. Valverde)

Que la tragedia sea presentida por el pueblo inunda comentarios en las obras procedentes del «rey poeta» que se sabe traicionado. En Henry $I V$ encontraremos una conspiración interna y externa que someten al Monarca a una continua erosión mural. El caos ha llegado al jardín. Ya no se oirán los ecos que inundaban las alegres travesuras de As You Like It. 
El mito de la «zona vegetal» desplaza la secuencia trágica» ${ }^{7}$ - como la denomina Kenneth Muir- e impone sus reglas del juego. Aquellos jardineros «descubiertos» por la Reina eran un preámbulo a la tragedia. Ahora es cuando el «estino del héroe» se nos muestra como una empresa ardua y difícil: saberse traicionado (Macbeth), compartir la vida con quienes desean la ruina moral del héroe central (Rey Lear) crea un clima especial de patetismo. Hablemos de «héroe descendente» para este Ricardo II, que como el Eduardo II de Marlowe, se hunde en tu destino de gobernante «literario», y cuantos datos queden en el escenario servirán de prueba para su derrota ${ }^{8}$. Ahora es el momento de entrar Hamlet. Recordar su modo de hacer justicia, su abnegada forma de resolver el conflicto. Hamlet decide entrar en acción una vez agotada su «vía dialéctica». Imagenémoslo en la actitud de quien desea por todos los medios que Elsinore sea lo que fue. Que el viejo Rey Hamlet «renazca».

Aquel gesto representa el momento de elección de Hamlet: La obra es una suma de instantes de ruptura con la ambigüedad. El camino a seguir se establece desde una teoría del comportamiento que no excluye la textualidad como apoyo en cada momento. Se llega con tales presupuestos a un ámbito de confusión de cada frase con su alrededor: elegir significa destruir un nexo, superar una contradicción, intentar un rumbo nuevo en una lucha por «romper con lo tópico». Hamlet, que vive la más absoluta contradicción, escoge su vocabulario para llegar a un fin: es la meta que alberga los resultados más prometedores, es el punto donde culmina una empresa destinada a hacer de cada pregunta una pregunta, a colocar el lenguaje en su propia situación de venganza y rebeldía. No sólo Hamlet busca un orden. Es el lenguaje, la frase, el menor signo de puntuación

7. Shakespeare's Tragic Sequence by Kenneth Murr. London: Hutchinson, 1972, 207 pp.

8. Esta idea de que el proceso de datos del escenario tienden a su propia resolución nos lleva a un punto mucho más atractivo: Dados unos héroes y un lenguaje se podría llegar a alcanzar unas metas dentro o fuera del escenario. Con este método haríamos del «ámbito escénico» una máquina de conversiones que pasaría por una necesaria oposición de fuerzas que se conjugan contra el proyecto inicial. Lo mismo Enrique VI, como Hermione o Bassanio, han de luchar contra una (adversidad» que les condiciona. Desde batallas o conspiraciones, hasta intentos de asesinato o acertijos lingüísticos, el horizonte de Shakespeare está vigilado por una continua y tenaz crítica. No hay nunca un orden establecido. La felicidad de los reyes (Ricardo II es buen ejemplo) o de los enamorados (Romeo y Julieta o Troilus y Cressida valen) dura muy poco. Hay una continua percusión de la tragedia sobre lo estable y así se llega a un punto de caos y catástrofe. Esta tesis no ha sido bastante analizada, pero quizá dos estudios la esbozan:

Patterns in Shakespearian Tragedy by Irving RIBNER. London: Methuen, 1960, 203 pp.

Shakespearian Tragedy by H. B. Charlton. Cambridge: At the University Press, $1971,246 \mathrm{pp}$. 
el que busca un sentido, el que está intentando llegar a un espacio de simetría donde se lea «el acto $X$ se escribe con la frase $S »$. Una vez conseguida esa identidad no es difícil escalar cumbres más remotas. Se trata de hacer de cada «ejercicio» de composición sintáctica un mecanismo donde los actos puedan integrarse: la venganza es una frase ( $\mathrm{A}$ quiere matar a $B »)$ y esa orden se debe colocar en el lugar que le corresponde. ¿No será entonces este escenario una máquina de situaciones? ¿No estaremos haciendo un ejercicio que consiste en dar a cada intención un resultado? ¿No será nuestro héroe ejemplo fiel de alguien que quiere insinuar a las palabras el sentido vengativo que tienen contra su propia inercia estática?

La conquista de un insinuante paisaje donde las palabras desplacen esa aureola de falsa divinidad que un espectro ocasiona: Es allí donde Hamlet se da cuenta de que su misión «renovadora» debe encuadrarse en un orden que incluye el «¿tú quién eres?» como punto de partida. La llegada a la identidad perdida, la sospecha de que tras esa denominación ritual (padre, madre, hermano, hermana, hijo...) exista un secreto oculto de dimensiones remotas hace que la semántica de Hamlet se vuelva ejercicio espectral de encontrar en las concavidades del lenguaje los reductos más atractivos: allí se coloca la acción lingüística, en el hueco que las palabras han dejado abandonado.

La construcción de un orden escénico está asegurada. Se llega desde la escena hacia una «teoría arquitectónica» que permite cobijar cuantas acciones ocurran. Sabemos que el orden de sucesión de unidades narrativas, base de la «teoría de información» del conjunto, no desdeña el planteamiento en canales sintácticos, hasta el extremo que de una mera frase se hace un «resultado» de posibilidades escritas que actuando desde los puntos básicos de la historia avanzan hacia puntos más comprometidos de la realidad. Hamlet domina la historia que se plantea, la rodea y soporta y hasta hace que se proyecte en los sucesivos «casos particulares» que después va a originar un sistema de preguntas y respuestas que llenan el «ciclo escénico». Tal sensación de que lo patente basta nos está diciendo que estamos ante un «espectáculo» de proyección de la frase en su ámbito sintáctico de idoneidad, nos descubre un mundo semántico nuevo e ignorado que no desdeña la realidad este ese príncipe y esa mujer: Hamlet habla con Ophelia, Hamlet habla de, Hamlet habla por, Hamlet habla sin, etc..., que llena con absoluta garantía un «diccionario» de posibilidades que como proyectos sucesivos de una sistemática de procesos alcanza en el resultado un pretexto para alcanzar el preámbulo informático. La construción de escenas propone entender ese «diálogo» como algo inherente a la literatura, pero que por ser «mecanismo de comunicación» 
no excluye a nadie, sino que hace de cada «caso particular» un momento de una consecución de metas y fines. Mencionar aquí el arte escénico como un «micromodelo político», tal y como lo entiende Morton A. Kaplan, no sería excesivo. Imaginar que bajo esa producción de frases en frase hay una conquista de fines por la palabra, nos parece obvio. Hacer de la sistemática textual un mecanismo de proyección del vocabulario en sus resultados harto evidente. El límite que separa la palabra del acto se tambalea. La voz busca un efecto en los demás. Ophelia responde.

La progresiva conquista de metas hace que Hamlet pueda considerarse como un ejercicio de programación: ahí están los logros, ante nosotros se esparcen por el escenario unos objetos que han sido utilizados y quedan inservibles. La meditada labor de «bautismo semántico» que el actor ejerce sobre su ámbito desemboca en un punto de ambigüedad. Los fines ya se conocen, la manera se somete a crítica y se hace que responda a toda la filosofía moral de la época. Así es como Hamlet debe dar cuentas al Parlamento de la Historia. Con esa forma de hablar recóndita y extraña ha de rendirse a los hechos. Este lenguaje es su forma de imitar el tono parlamentario que se ha alcanzado en Inglaterra en 1600. Pero igual que años después Cromwell destruirá la retórica de Carlos I con nuevas frases, de la misma manera el tono dialéctico de Hamlet inaugura una época en la que los actos deben suceder a las palabras. La praxis queda expuesta como el límite activo del texto. Hamlet, en su actuación dinámica, somete la Historia a su método implacable, hace de cada destino un código verbal.

Y en las obras finales este método se afianzará. Cuando repasamos Cymbeline sentimos una «paráfrasis» continua ${ }^{9}$, un deseo de «deshacer lo evidente» y con ello se alcanza el estadio de clarividencia, muy en la línea del Duque de Viena en Measure for Measure. Rasgar la información del texto, conseguir que cada palabra desvele su identidad lleva a un ejercicio brutal de «apoteosis moral» donde la victoria de Bassanio o de Sebastián sirven de contrapunto a los «amores descarriados» del Príncipe Hall cuando el pueblo lo educaba. La voz de Falstaff tiene el encanto perenne de un latido del corazón de Inglaterra. Su lección consiste en educar a los espectadores para que acepten a un monigote como futuro Enrique V. La información del texto, la consideración de Henry IV como mecanismo de defensa de la mass media frente a la «gramática oficial» tiene momentos de esplendor, y hasta observarlo como «juego semántico»

9. “By "paraphrase", them, I understand a relation that a sentence $a$ bears to a sentence $b$ if and only if $a$ means the same as $b$. So, if $a$ is a paraphrase of $b$, then $b$ is a paraphrase of a.m Foundations for an Adequate Criterion of Paraphase by Rita Nolan. The Hague: Mouton, 1970, p. 15. 
ofrecería unos cauces inéditos. Advertir en esa profusión de lenguajes un «mecanismo de conversión», seguimos aquí a Jaakko Hintikka ${ }^{10}$, sería atractivo y original.

La línea se mantiene, desde el orden (sintáctico) se llega al caos (semántico). La consideración de las obras de Shakespeare como un mecanismo para alcanzar respuestas nos dejaria al descubierto un modo especial de entender el lenguaje dramático. Hacer de unas frases motivo de actuación nos ofrecería ocasión para crear una «dinámica dramática» que desde esa situación «un rey, A, B y C» produjera una reacción determinada. Este modo de observar al escenario, con la misma desconfianza con la que Roland Barthes analiza un texto, nos da ocasión a pensar que lo mismo The Tempest como The Winter's Tale son obras donde «encontrar lo perdido» lleva a un nivel de «lenguaje restaurado». El regreso de Próspero a Milán no tiene más sentido que hacer del poder perdido un motivo de reflexión moral. La analítica de los hechos, tal y como los narra Ferdinand, es del todo distinta. Es como encontrar otra dimensión de una misma realidad. La traducción de un lenguaje en otro es empresa imposible. La construcción de un molde común, una utopía. La «máquina de convertir palabras en palabras» avanza implacable produciendo nuevas sorpresas ${ }^{11}$.

Y la mayor será observar que Hamlet recurre al teatro para llevar a cabo su propósito y ante los ojos asombrados del Rey Claudius «representa» el pasado en un intento de hacer del teatro método de «llegar a la verdad». Con tales evidencias estamos ante un arte donde los acontecimientos borrados (por lo indigno) pueden reaparecer, y Troilus verá a Cressida desnuda con Diomedes de la misma forma que, por ejemplo, los Talbot se encontrará en la batalla de Henry $I V$. Hablemos entonces de un auténtico proceso de datos que hace de los acontecimientos «rupturas de un orden establecido» y coloca las incidencias en actitud de «pregunta hostil». Como si se tratara de observar el teatro desde un nuevo ángulo lingüístico, como datos que llevan a signos. Voces tales como

10. "The basic problem is to find some suitable symmetry principles which enable us to distinguish from each other the different possibilities that certain given resources of expression enable us to distinguish from each other. It seems to me that insofar as we have an unambiguous concept of (semantic) information of which serious theoretical use can be made, it must be based on such distinctions between different cases, perhaps together with a system of "weight" (probabilities a priori) given to these different possibilities.» "On Semantic Information» by Jaakko HinTikKa. Information and Inference. Edited by Jakko Hintikka and Patrick Suppes. Dordrecht: D. Reidel Publishing Company, 1970, p. 5.

11. Grammar, Meaning and the Machine Analysis of Language by Yorick Alexander WiLKs. London: Routledge, 1972, $198 \mathrm{pp}$. 
«entra», «sale», «aparte», etc... adquieren valor gramatical, son «indicadores» de función. Señalan como tantos hitos del camino del sistema escrito ${ }^{12}$.

Cualquier proyecto en Shakespeare lleva a Hamlet, que es como un mecanismo productor de lenguajes. El tema de la culpa en cualquier rincón de una de sus obras debe orientarse hacia Elsinore. Inocencia, venganza, oración, súplica, etc... conducen a la historia de este nuevo Orestes ${ }^{13}$. Y cuando veamos un padre como Pericles que busca «lo perdido», pensemos que el príncipe de Dinamarca también quería completar su amor familiar. Meditemos que la actitud de Hamlet es la de otros príncipes (Ferdinand, Troilus, Hal...) tratando de vivir a la vez de «ficción» del poder y de la libertad humana ${ }^{14}$. Y cuando en una isla, en las latitudes cósmicas de The Tempest, se llegue a la construcción de una nueva «Edad de Oro», podemos creer que estamos ante una apoteosis que cierra un esfuerzo estéril: la vuelta del destronado a su trono es como una metáfora del intento de Shakespeare de «recuperar lo perdido», y hasta añorar una vida eterna —-Próspero lo insinúa— donde no exista ya más milagro que la existencia perenne.

El orden de los acontecimientos lleva a otro «orden». La anfibología nos ha estado entregando una necesaria ambigüedad. Caliban y Ariel exponen su nuevo lenguaje, sus deseos de imponer un vasallaje al «gran teatro del mundo» ${ }^{15}$. El futuro es incierto y ese orden que se busca con anhelo (alguien habló de la «música de las esferas») se desvanece como imposible. Y es entonces cuando la paz y la armonía avanzan hacia la modificación y el conflicto. Es el instante de derribar a Leviathan y que surja en la sublevación contra Julio César un «orden nuevo» que será el mismo que Hesiodo explica y hasta después la Commonwealth de

12. Theory of the Linguistic Sign by J. W. F. Mulder and S. G. J. Hervey. The Hague: Mouton, 1972, $70 \mathrm{pp}$.

13. "The play of Hamlet surely balances on the prayer-scene. Hamlet has the proof of Claudius's guilt which he had demanded. Claudius is there before him, an easy prey; he moves in to kill him, pauses, reflects, and decides not to act.o Shakespeare and the Confines of Art by Philip Edwards. London: Methuen, 1968, p. 88.

14. "On the other hand, though the things Hamlet endures may not work a spiritual revolution in him they do have effect on the given ingredients of his mind. And that effect has its own order.m Shakespeare's Problem Plays by E. M. W. Trulyard. Harmondsworth:Penguin Books, 1970 (1950), p. 25.

Contrastar esta idea con el consejo de Hamlet a los actores «que la acción corresponda a la palabra y la palabra a la acción»).

15. "Above all is this true of the characters, specially the mythical ones most eagerly seized upon- Ariel and Caliban. Where does the beauty of greatness of these creation lie if not in their reality? They are not single abstraction personified, but many-sided conceptions incarnated», en (The Tempest) by E. E. SToLL. Twentieth Century Interpretations of "The Tempest» (Edited by Haller Smith). EnglewoodCliffs, N. J.: Prentice-Hall, 1969, p. 26. 
Cromwell mostrará en su versión del Paradise Lost. El sentido del teatro de Shakespeare es a la vez ejemplo y cauce, método de exposición y cláusula didáctica y hace que toda su obra esté sujeta a una vigilancia especial por parte del poder: Richard II pudo tener consecuencias inmediatas en Essex. The Tempest pudo ser una apología del monarca mago Jacobo I.

Esta presencia de la historia en el teatro se realiza desde un orden social que vigila a Hamlet, que lo contradice o respeta. La actuación del héroe, su movilidad en la escena, es la biografía de toda la humanidad. La conspiración que le acecha, los falsos lenguajes, la presencia del tirano, son «emblemas» de una visión política de los hechos ${ }^{16}$. EI mero hecho de que Miranda, la única mujer en The Tempest, se enamore nada más ver a Ferdinand, deja bien a las claras que en la isla política hay un deseo de «paz familiar» ${ }^{17}$. La idea de una armonía, que se desvela en The Faerie Queene y deja patente una doctrina que desde Mirror for Magistrates hasta los textos de Holinshed intenta hacer del pasado un educador del presente, y de los reyes, seres humanos como nosotros. Enrique IV se comporta, una vez que abandona el poder, como un padre que dolorido por la conducta de su hijo le recrimina su conducta. Romeo se

16. La realidad de un mundo de conspiración nos llevaría hacia obras como Richard II, Macbeth o Julius Cesar. En la actuación de Próspero no hay muchos elementos de (teoria del poder), de modo que aproximarlo a su más cercano ejemplo, el Rey Lear, sería justo. La forma de integrar el mito del (divine ruler» con esta manera espontánea de obrar hace de Próspero un ejemplo de personaje que a través de la recriminación consigue sus metas. Su moral es (restituir y perdonar». Volver al ducado de Milán es como regresar a una patria perdida.

"The two continuities, sovereignty-conspiracy and slavery-freedom, are also alike in the fact that their metaphorical force is expressed through scenes that are just one step removed from allegory. The more serious of the restorations and releases convey similar kind of moral meaning. Ferdinand's release from "wooden slavery" signifies tha the is a true prince.) (The Mirror of Analogy) by Reuben A. Brower, en: Shakespeare's Later Comedies. Edited by D. J. Palmer. Harmondsworth: Penguin Books, 1971, p. 420 .

Esta idea de Brower es interesante: Hace de la simbología de la «pérdida del estado de esclavitud» un símil valioso: Tal empeño nos llevaría The Tempest hacia un punto de ruptura con la Arcadia, en cuanto a componente natural se refiere, y hasta veriamos a Próspero, quien rompe con las leyes que signifiquen opresión y aniquilamiento. ¿Quiere Shakespeare insinuar que eso sólo se consigue a través de la magia?

17. La relación de Próspero con los demás daría lugar a un grafo de interconexiones del todo interesante y revelador. Su modo de hablar lleva a ser el único foco «indiscutible» de todo el sistema de información. Ariel y Miranda realizan una labor de favorecer su (relato» y hasta Ferdinand con sus actos colabora en un método que de mecanismo moral se hace «teoría de la restauración política). Próspero da a cada situación su (traducción simultánea), es un magnifico manipulador de cuanto ocurre en esa isla. Analizar este diálogo Ferdinand-Miranda desde un sistema de cdoble semiótica», (doble información», "doble comportamiento». Ambos desconocen la función de sus palabras.

Javier Sánchez Escribano, en su memoria de licenciatura (Universidad de Zaragoza, 1974), hizo observaciones muy interesantes sobre el particular. 
expresa como cualquier enamorado que pretende poseer la belleza. En el centro de su actuación, sin embargo, se ha acumulado todo el peso de una mitología implacable, un fatum adverso, una catástrofe inminente ${ }^{18}$. Su deseo de «romper con el mundo» se desarrolla desde la «magia» de Fray Lorenzo y su intención de superar la enemistad de las dos familias es tan banal como un Troilus que aprendiera a hablar el griego. El orden de los acontecimientos en Shakespeare, implacable y lógico, imprevisto y brutal, explica desde un pequeño teatro de madera junto al Támesis el mismo «orden de la historia».

18. La obra se extiende hacia siete espacios: lo transcurrido fuera queda olvidado por el autor, que dirige toda su atención hacia la (zona femenina) del drama: La casa de Julieta y su jardín adquieren signo básico en esta sinfonía de amor imposible. La misma estructura de la obra, su disposición en actos y escenas, le dan una curiosa simetría, una cierta tendencia a que los ejemplos de cinco escenas sean la base, sólo roto este plan en los actos segundo y quinto. Hasta el proyecto fallido de unos coros que abren los actos primero y segundo nos señala que estamos ante una construcción que tiende a reflejar la sociedad del lugar. Un espacio que el poder del príncipe de Verona tiene inmovilizado. En tales circunstancias, llegar a la catástrofe significa alcanzar un punto de paz familiar. Concertar un punto de equilibrio. El Dr. Conejero en Shakespeare: Orden y Caos (Valencia: Fernando Torres, 1975) analiza esta cruptura de armonía» con brillantez y profundidad. 